\title{
Rutting evaluation of rubberized and SBS modified porous asphalt mixtures
}

\author{
Hassan Ziari, Bahram Shirini* and Reza Imaninasab
}

School of Civil Engineering, Iran University of Science and Technology, Tehran, Iran

\begin{tabular}{|c|c|}
\hline $\begin{array}{l}\text { ARTICLE INFO } \\
\end{array}$ & A B S T R A C T \\
\hline $\begin{array}{l}\text { Article history: } \\
\text { Received } 6 \text { January, } 2015 \\
\text { Accepted } 2 \text { June } 2015 \\
\text { Available online } \\
\text { 4 June 2015 } \\
\text { Keywords: } \\
\text { Porous asphalt } \\
\text { Permeability } \\
\text { Rutting resistance } \\
\text { Wheel tracking }\end{array}$ & $\begin{array}{l}\text { The aim of this research is to investigate the impact of crumb rubber and Styrene-Butadiene- } \\
\text { Styrene (SBS) on rutting potential of porous asphalt mixtures. Optimal binder content of } \\
\text { control mix, 5\% SBS, and mixtures containing } 10 \%, 15 \% \text {, and } 20 \% \text { of crumb rubber were } \\
\text { determined using Cantabro Loss test. Dynamic creep, wheel tracking, draindown, and falling- } \\
\text { head permeability tests were then carried out on specimens to examine rutting resistance, } \\
\text { resistant to draindown, and permeability. SBS modified and } 10 \% \text { rubberized asphalt satisfied } \\
\text { all the requirements of porous asphalt design criteria. They also have similar rutting } \\
\text { performance, permeability. Except for rutting performance, } 10 \% \text { rubberized asphalt has the } \\
\text { best performance. Instead, asphalt mixture containing } 20 \% \text { crumb rubber was the most mixture } \\
\text { against rutting resistance. }\end{array}$ \\
\hline
\end{tabular}

(c) 2015 Growing Science Ltd. All rights reserved.

\section{Introduction}

Porous asphalt is gap-graded coarse mixture containing approximate air void content of $20 \%$. It is mainly used for water drainage, which avoids puddle formation and improves sight vision while raining. Moreover, sound absorption property causes noise reduction and increases friction. Safety is enhanced due to drainage properties improvement and Hydroplaning phenomenon removal by porous asphalt mix (PIARC, 1993). Regarding functional properties, structural deficiency of this type of mixture increases life cycle cost compared to conventional dense-graded asphalt mix. Stone-on-stone contact of coarse aggregate skeleton bears axle loads that is not stable at higher temperature to prevent rutting (Santucci, 2001). In addition, aging intensifies as a result of larger surface exposed to air and it accelerates oxidation. Draindown is another problem of gap-graded asphalt mixtures, which is required to be controlled. In the past three decades, in order to improve the performance of asphalt mixtures polymer modifiers have been widely investigated (PIARC, 1993). Low Density Polyethylene (LDPE), which is the main element of plastic pocket, was found to have a positive effect on not only resistance properties of porous mixture such as draindown, rutting, and moisture susceptibility, but also on environment by effective recycling disposal materials (Punith \& Veeraragavan, 2007). A combination

* Corresponding author.

E-mail addresses: bahram.shirini@gmail.com (B. Shirini) 
of Cellulose fiber and Reclaimed Polyethylene Modified Binder (RPMB) was proved to improve fatigue life, rutting and moisture damages resistance of porous asphalt mix (Punith et al., 2011). SBS is recommended to decrease high temperature rutting (Akbulut \& Gürer, 2007; Nielsen et al., 2005). Using waste polymer of rubber is also considered particularly beneficial since rubberized asphalt mixtures are environmentally friendly due to recycling used tire and service life increase (Oliveira et al., 2013; Takallou \& Sainton, 1992).

Numerous studies have been conducted on performance of mixtures containing rubberized and SBS modified binder. All indicate its usefulness on enhancing rutting resistance, aging, fatigue behavior, and moisture susceptibility (Xiao \& Amirkhanian, 2010; Xiao et al., 2009, 2010). Others have also investigated the fatigue behavior, cold cracking, durability and environmental specifications of asphalt concretes or concretes containing polymeric binders (Ameri et al., 2012; Heidari-Rarani et al., 2014; Aliha et al., 2014,2015; Sol-Sánchez et al., 2015; MansourKhaki et al. 2015) In this study, rubberized binder at different percentages and SBS modified binder at 5\% were used in order to find their effect on rutting performance of porous asphalt. Moreover, influence of theses polymers on designing parameters was investigated.

\section{Materials}

Physical properties of used Lime aggregates are presented in Table 1. Particle size distribution is also given in Fig. 1, which falls within the upper and lower limits of the proposed gradation of Iran Highway Asphalt Paving code 234 (IHAP code, 2003). Properties of used performance grade (PG5822) bitumen are also presented in Table 2. In addition, it is indicated in Table 3 that penetration decreases and softening point increases by crumb rubber (CR) content increase. It shows that stiffer binder is resulted using rubber.

Table 1. Aggregate Physical Properties

\begin{tabular}{lll}
\hline Measured Properties & Standard (ASTM) & value \\
\hline Bulk specific gravity of coarse aggregate $\left(\mathrm{gr} / \mathrm{cm}^{3}\right)$ & C127 & 2.59 \\
Bulk specific gravity of fine aggregate $\left(\mathrm{gr} / \mathrm{cm}^{3}\right)$ & $\mathrm{C} 127$ & 2.32 \\
Water absorption of coarse aggregate $(\%)$ & $\mathrm{C} 127$ & 2.2 \\
Water absorption of fine aggregate (\%) & $\mathrm{C} 127$ & 2.4 \\
Los Angeles abrasion value (\%) & $\mathrm{C} 131$ & 22.3 \\
Percentage of Fractured Particles in one side & D5821 & 97 \\
Percentage of Fractured Particles in two sides & D5821 & 94 \\
\hline
\end{tabular}

Table 2. Binder Properties

\begin{tabular}{lll}
\hline Measured Properties & Standard (ASTM) & Value \\
\hline Penetration at $25^{\circ} \mathrm{C}(0.1 \mathrm{~mm})$ & D5-73 & 64 \\
Softening point $\left(\mathrm{R} \& B{ }^{\circ} \mathrm{C}\right)$ & $\mathrm{C} 36-76$ & 53 \\
Ductility at $25^{\circ} \mathrm{C}(\mathrm{cm})$ & $\mathrm{D} 113-79$ & $>100 \mathrm{~cm}$ \\
Density at $25^{\circ} \mathrm{C}\left(\mathrm{gr} / \mathrm{cm}^{3}\right)$ & $\mathrm{D} 70-76$ & 1.05 \\
Flash point $\left({ }^{\circ} \mathrm{C}\right)$ & $\mathrm{D} 92-78$ & 308 \\
\hline
\end{tabular}

Table 3. Penetration and softening point at different concentrations of crumb rubber

\begin{tabular}{llll}
\hline Properties & CR-10\% & CR-15\% & CR-20\% \\
\hline Penetration at $25^{\circ} \mathrm{C}(0.1 \mathrm{~mm})$ & 40 & 32 & 30 \\
Softening point $\left(\mathrm{R} \& \mathrm{~B}{ }^{\circ} \mathrm{C}\right)$ & 58 & 67 & 71 \\
\hline${ }^{*} \mathrm{CR}-10 \%, \mathrm{CR}-15 \%$, and $\mathrm{CR}-20 \%$ are asphalt cement samples containing $10 \%, 15 \%$, and $20 \%$ crumb rubber, respectively.
\end{tabular}




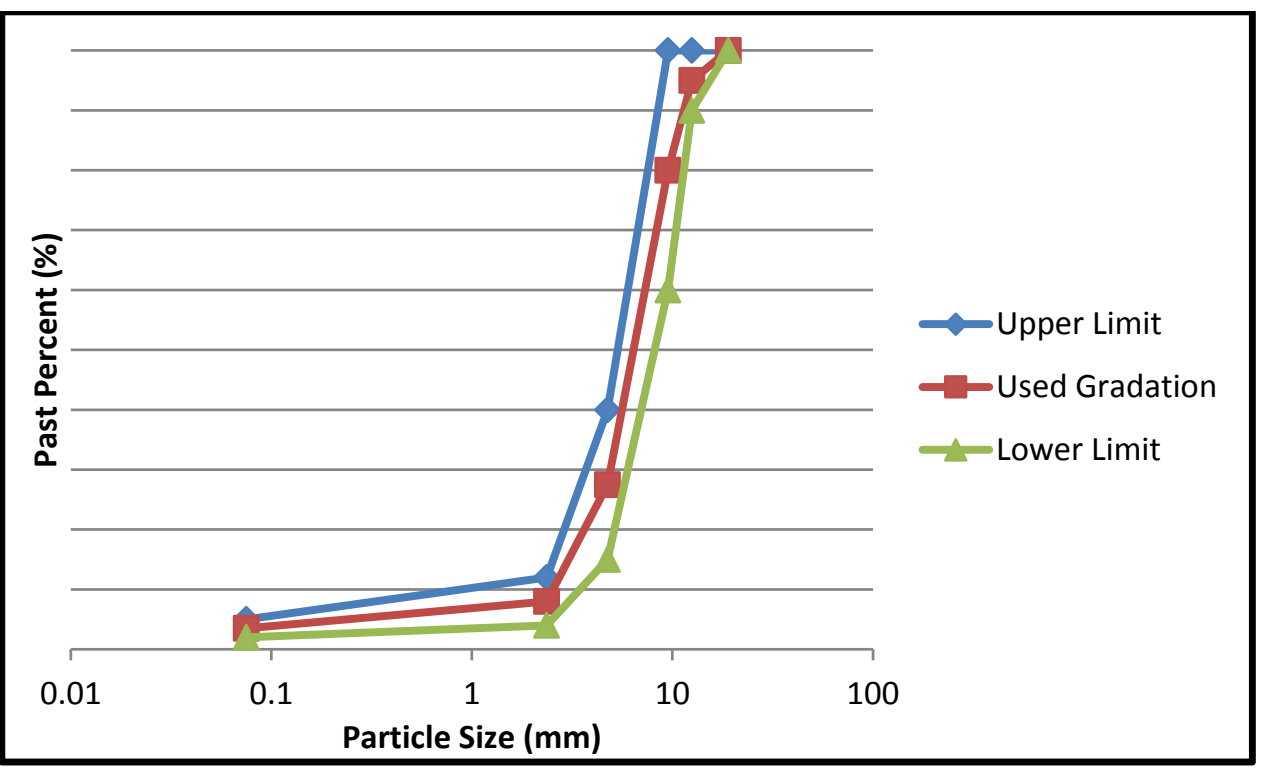

Fig. 1. Particle size distribution

\section{Experimental setup and procedure}

\subsection{Rubberized binder preparation}

In wet process, high-speed stirrer apparatus is used to blend rubberized binder. In this research, 40 mesh rubber at concentration of $10 \%, 15 \%$, and $20 \%$ were added to the virgin binder at reaction temperature of $180^{\circ} \mathrm{C}$ and a reaction speed of $3500 \mathrm{rpm}$ for 30 minutes (Panda \& Mazumdar, 2002). It was shown earlier that the blended binder properties are not affected by time after half an hour (Xiao et al. 2006). SBS was also blended as crumb rubber.

\subsection{Sample fabrication}

In this research, cylindrical samples with a diameter of $100 \mathrm{~mm}$ and approximate height of $67 \mathrm{~mm}$, which weight of 1000 gr, were fabricated by Suprepave Gyratory Compactor (SGC) with setup parameters presented in Table 4 (Brown \& Cooley, 1999). Control, 5\% SBS modified, 10\%, 15\%, and $20 \%$ rubberized samples were used at binder content of $4.5 \%, 5 \%, 5.5 \%$, and $6 \%$ to determine the optimal binder content for each type of mixture. Three identical samples were prepared for each percentage and the average was calculated as the measured value of different tests.

Table 4. Setup parameters of Suprepave Gyratory Compactor

\begin{tabular}{ll}
\hline Setup Parameters & Value \\
\hline Stress level (kPa) & 600 \\
Number of Gyration & 50 \\
Angle (degree) & 1.25 \\
Rotational speed (rpm) & 30 \\
\hline
\end{tabular}

\subsection{Cantabro test}

This test was performed with accordance to standard ASTM C131 to determine optimal binder content of porous asphalt mix. In this test, specimens went through 300 rotations at rotational speed ranges between 30 to $34 \mathrm{rpm}$ by Los Angeles Apparatus. It is carried out without steel spheres at $25^{\circ} \mathrm{C}$. The result is the weight loss calculated by Eq. (1) as follows,

$$
C L=\frac{A-B}{A} \times 100
$$


where $A$ is the initial weight, $B$ is the retained weight, and $C L$ is the Cantabro Loss (\%).

Optimal binder content is the average of binder contents that relates to $18 \%$ air void content and 20\% Cantabro Loss. However, any binder content that falls within these two specification limits is an acceptable optimal binder content. Mixtures at selected optimal binder content must satisfy following criteria:

(1) Minimum air void of $18 \%$

(2) Maximum CL of $20 \%$ for un-aged specimens.

\subsection{Draidown test}

This test is performed on specimens to check whether they exceed the limited value of $0.3 \%$ or not (Smith, 1992). According to standard AASHTO T305-97, un-compacted mixture at optimal binder content is placed into a wire basket with a tray underneath and experiences one hour at a temperature $10^{\circ} \mathrm{C}$ above the production temperature. The amount of draindown is then calculated by Eq. (2) as follows,

$$
D R=\frac{D-C}{B-A} \times 100
$$

where $D R$ is the amount of draindown, $A$ is the wire basket weight, $B$ is the sample weight plus wire basket, $C$ is the tray weight, and $D$ is the tray weight after an hour in the oven.

\subsection{Falling-head permeability test}

Permeability of porous asphalt mix is particularly important as this function is the main reason of using it. Minimum Coefficient of permeability is proposed $100 \mathrm{~m}$ /day with accordance to NCAT Report (Kandhal \& Mallick, 1999). This coefficient is obtained by performing falling-head permeability test with accordance to ASTM D3637 on cylindrical sample with diameter of $15(\mathrm{~cm})$ and approximate thickness of $8(\mathrm{~cm})$. The used specimens were also fabricated by SGC and the test is performed three times on each specimen. Eq. (3) yields the formula that the coefficient of permeability or hydraulic conductivity is computed:

$$
k=t_{c} \times \frac{a \times L}{A \times t} \times \ln \left(\frac{h_{0}}{h_{t}}\right)
$$

where:

$k$ : $\quad$ Coefficient of permeability $(\mathrm{cm} / \mathrm{s})$

$a$ : $\quad$ Area of pipe $\left(\mathrm{cm}^{2}\right)$ that is equal to $20.428 \mathrm{~cm}^{2}$

$L: \quad$ Length of specimen $(\mathrm{cm})$

A: $\quad$ Area of specimen $\left(\mathrm{cm}^{2}\right)$ that is equal to $176.417 \mathrm{~cm}^{2}$

$t$ : $\quad$ Elapsed time of test (sec)

$h_{0}$ : Head of beginning of test that is equal to $103.3(\mathrm{~cm})$

$h_{t}$ : Head at end of test that is equal to $29.7(\mathrm{~cm})$

$t_{c}$ : Corrective coefficient for test temperature other than $20^{\circ} \mathrm{C}$ 


\subsection{Dynamic Creep test}

The aim of dynamic creep test is to evaluate rutting resistance of asphalt mixtures. Permanent deformation versus cycle cure is the most important output of the test that is related to rutting resistance. It should be noted that the cumulative strain is not equal to measured rut depth and is considered as a criterion for rutting resistance comparison of different mixtures.

In this study, the software of UTM-5 at Iran University of Science and Technology developed according to Australian code, AS-2891.12.1 was used to carry out the test. The test specimens were kept at least 5 hours at $40^{\circ} \mathrm{C}$ temperature. Setup parameters of Dynamic creep test are presented in Table 5.

Table 5. Dynamic Creep test parameters

\begin{tabular}{ll}
\hline Parameter & Value \\
\hline Loading pattern & Rectangular \\
Loading period & $500 \mathrm{~ms}$ \\
Rest period & $1500 \mathrm{~ms}$ \\
Contact stress & $10 \mathrm{kPa}$ \\
Applied repeated stress & $200 \mathrm{kPa}$ \\
Termination criteria & 400000 cycles of load repetition or $300000 \mu \mathrm{s}$ \\
\hline
\end{tabular}

\subsection{Wheel tracking test}

Wheel track is a simulative test to predict measured rut depth (Stuart \& Mogawer, 1997). In this research, wheel tracking test was performed to evaluate control and modified mixtures rutting resistance. The test was carried out according to BS 589-110 code. Three compacted slabs with dimensions of $300 \times 300 \times 50(\mathrm{~mm})$ were prepared for each type of mixture at optimum binder content and $18 \%$ to $20 \%$ air void content. According to Hamburg test specification, the temperature for PG58-22 is performed $45^{\circ} \mathrm{C}$. Slab samples were kept in test temperature of $45^{\circ} \mathrm{C}$ at least for 6 hours. Rut depth was measured after 8000 cycles.

\section{Results and discussion}

\subsection{Mix design results}

Since higher binder content increases the thickness of asphalt film on aggregate surface, increase of cementitious material, as shown in Fig. 2, results in more cohesive mixtures. Consequently, more abrasion resistant mixtures are obtained. Fig. 3 illustrates that more binder content, however, reduces the air void content which is not allowed to be less than $18 \%$. Although, at concentrations of $15 \%$ and $20 \%$, there are no binder contents for $18 \%$ air void, they can be computed by introduced trend lines. It can be inferred from Fig. 2 that at lower asphalt binder dosage, Cantabro Loss weights of rubberized mixtures are far greater than that of control mixture. However, they approach it at high dosage of $6 \%$.

Fig. 4 shows that almost all mixture types satisfy minimum air void content requirement except two that are negligibly below the $18 \%$ limit. Finally, optimal binder contents are presented in Fig. 3. Rubberized mixtures do not have greater optimal binder content than control mixture up to the dosage of $10 \%$. However, $15 \%$ crumb rubber increases optimal binder content $0.6 \%$ compared to control one. More crumb rubber results in reduction. Tables 6 and 7 present the trend lines for Cantabro test and air void content, respectively. 


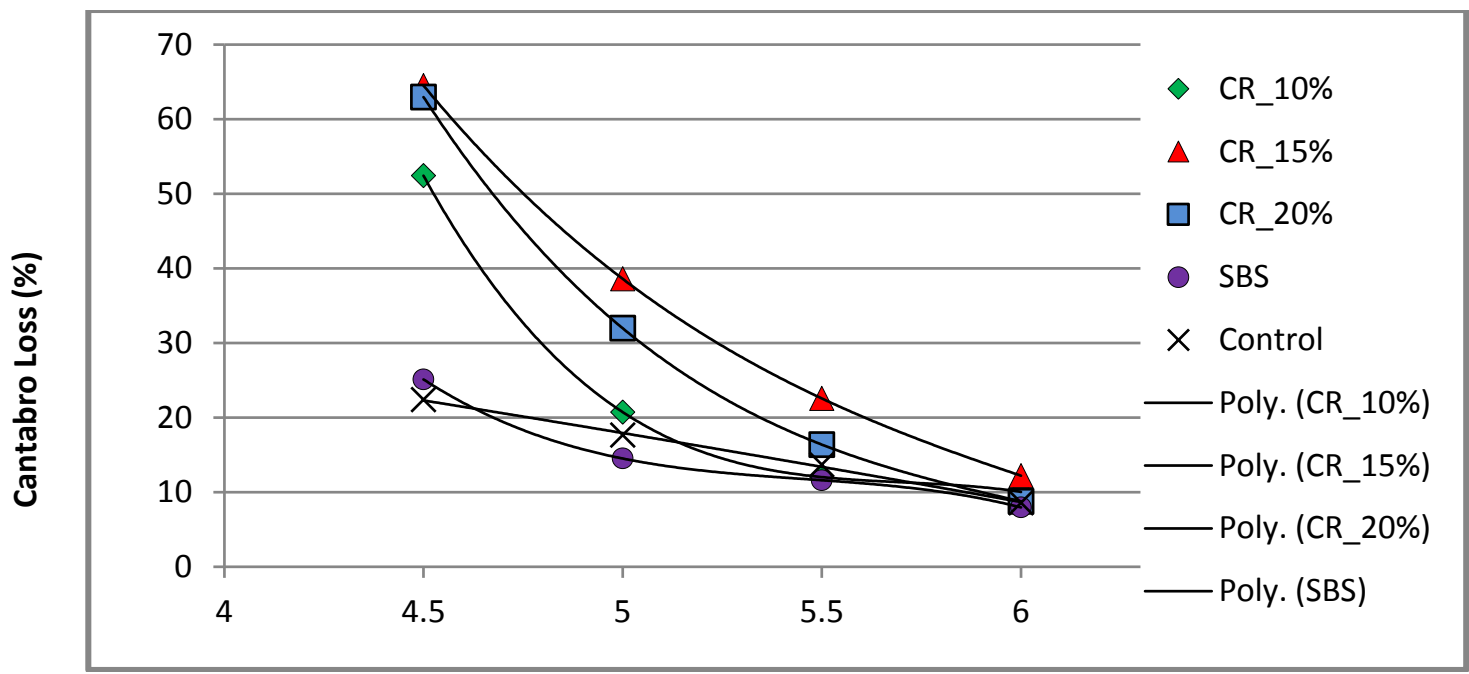

Fig. 2. Cantabro test results

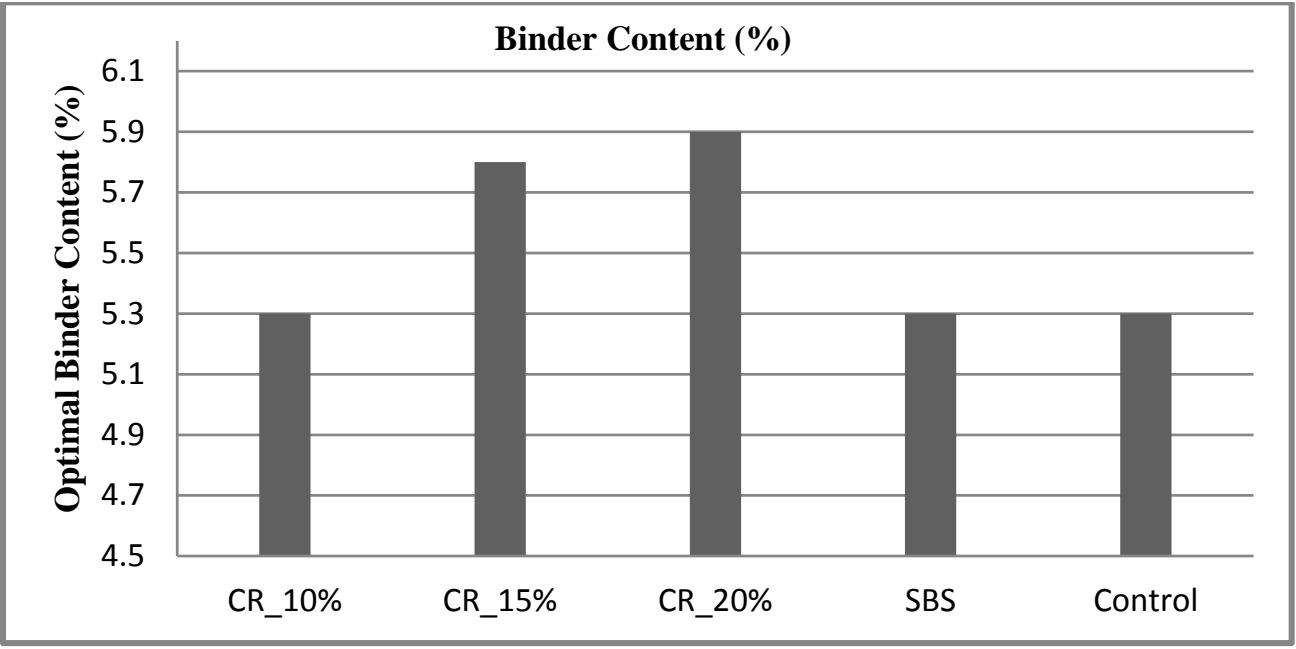

Fig. 3. Optimal Binder content

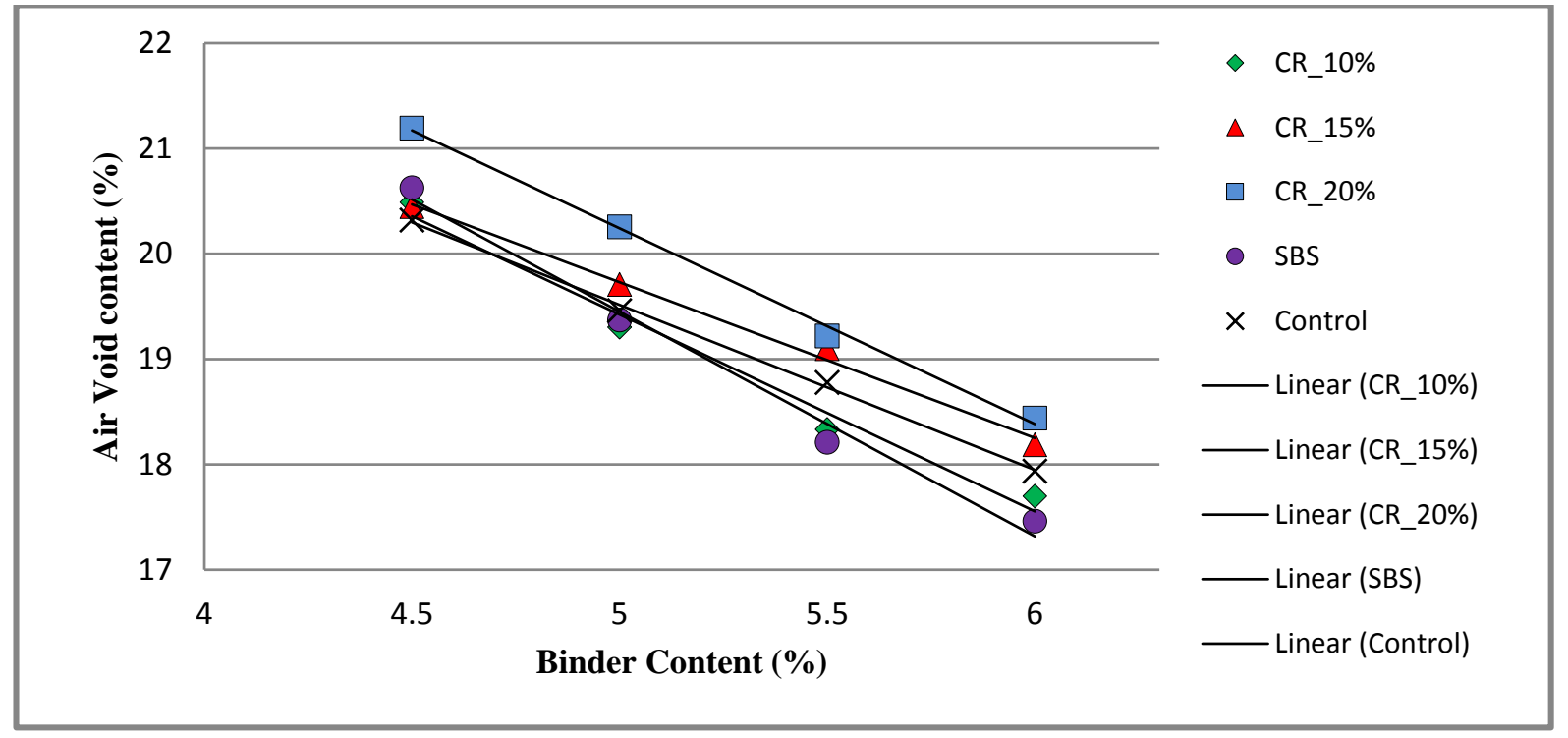

Fig. 4. Air void content results 
Table 6. Cantabro test trend lines

\begin{tabular}{lll}
\hline Mixture type & Regression equation & R-squared \\
\hline CR-10\% & CL(\%) $=-21.655(B C)^{3}+370.77(B C)^{2}-2118.5(B C)+4051.1$ & 1 \\
CR-15\% & CL(\%)=-5.588(BC) $)^{3}+103.57(B C)^{2}-657.17(B C)+1433.6$ & 1 \\
CR-20\% & CL $(\%)=-9.8927(B C)^{3}+179.21(B C)^{2}-1094.3(B C)+2259.7$ & 1 \\
SBS & CL $(\%)=-11.232(B C)^{3}+183.86(B C)^{2}-1006.9(B C)+1856.6$ & 1 \\
Control & CL(\%) $=-0.3466(B C)^{2}-5.4433(B C)+53.82$ & 0.9982 \\
\hline
\end{tabular}

Table 7. Air void Content trend line

\begin{tabular}{lll}
\hline Mixture type & Regression equation & R-squared \\
\hline CR-10\% & VA(\%) $=-1.8684 x+28.765$ & 0.9826 \\
CR-15\% & VA(\%) $=-1.4795 x+27.128$ & 0.994 \\
CR-20\% & VA(\%) $=-1.8594 x+29.539$ & 0.9971 \\
SBS & VA(\%) $=-2.1323 x+30.111$ & 0.988 \\
Control & VA(\%) $=-1.5676 x+27.353$ & 0.9981 \\
\hline
\end{tabular}

\subsection{Draindown test results}

As shown in Fig. 5, all mixtures satisfy maximum allowable requirement of 0.3 regarding draindown. Increase of crumb rubber content decreases the amount of draindown since rubber improves thermal sensitivity of asphalt cement by increasing its viscosity.

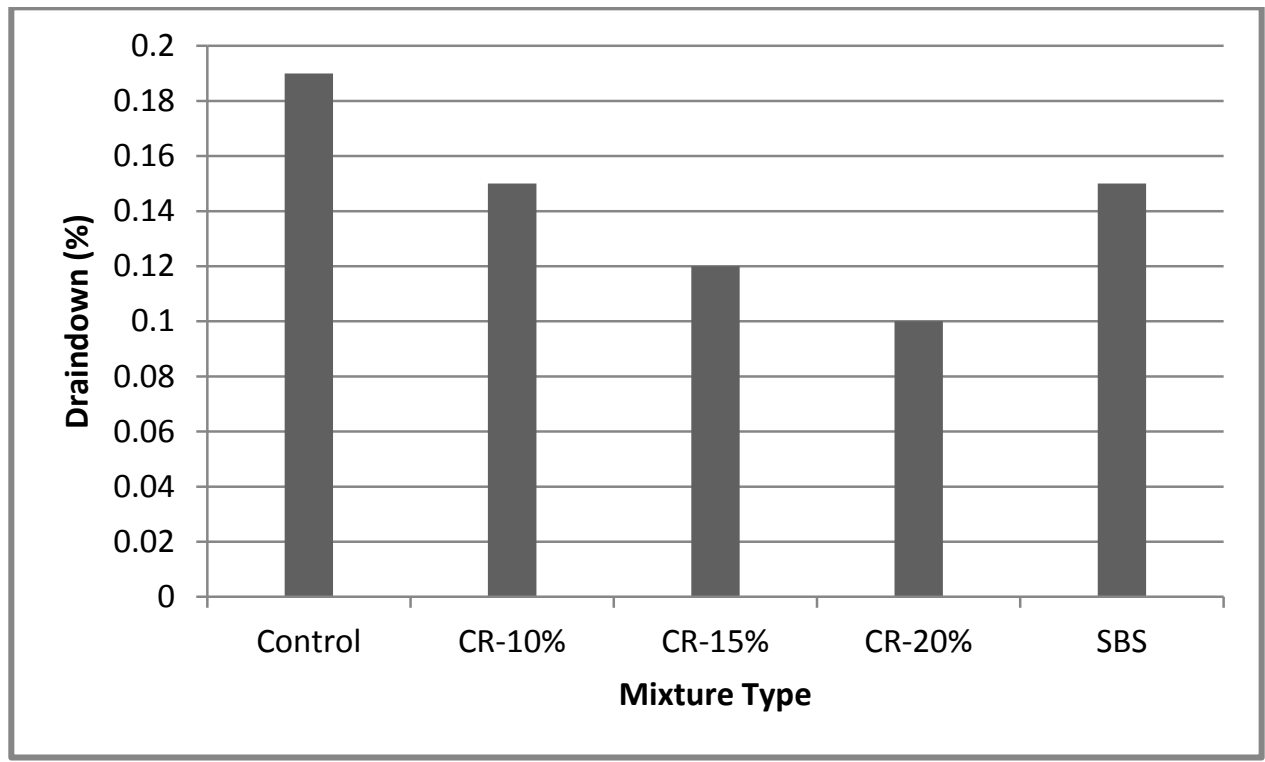

Fig. 5. Draindown test Results

\subsection{Permeability test results}

As shown in Fig. 6, the falling-head Laboratory permeability test results indicate that control , SBS modified, and $10 \%$ crumb rubber mixtures satisfy minimum requirement of allowable coefficient of permeability (100 m/day). Coefficient of permeability reduces with crumb rubber dosage increase at the same air void content. It shows that rubberized asphalt cement is more resistant against water flow. 


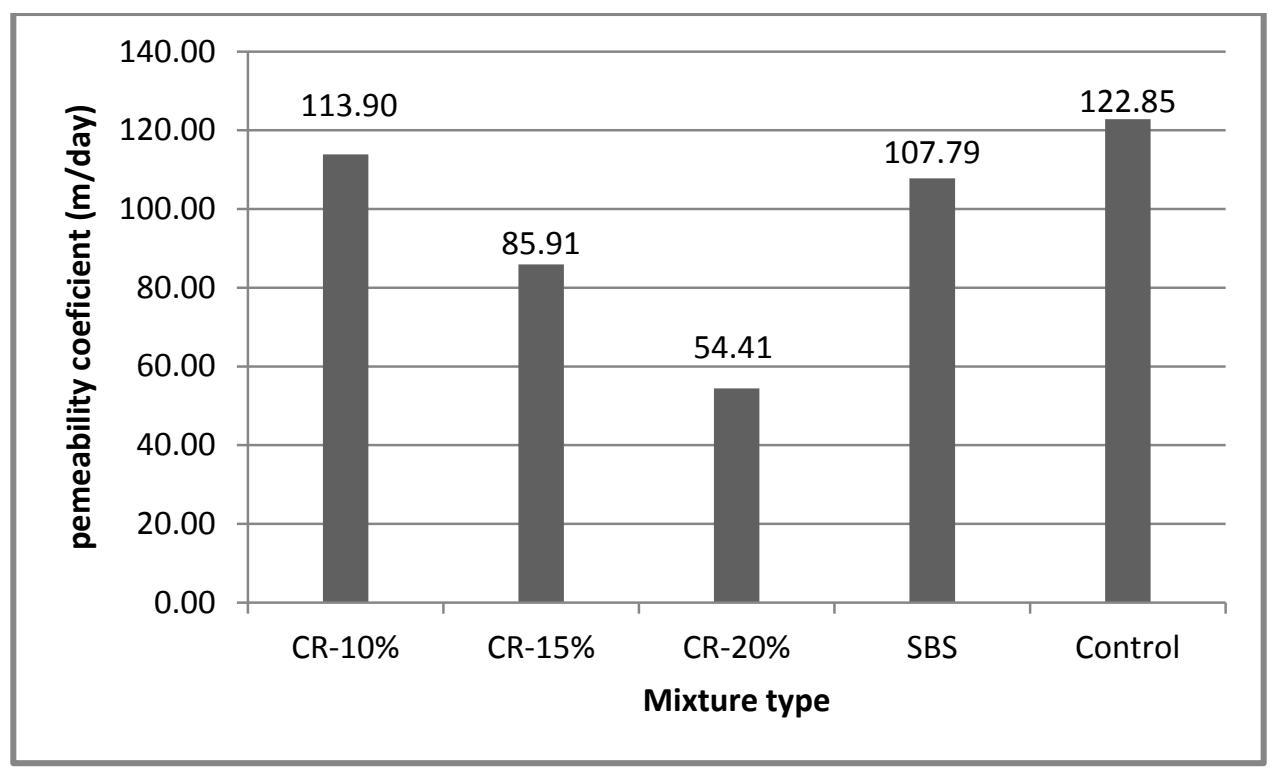

Fig. 6. Permeability test results

\subsection{Dynamic creep test results}

Rutting resistance is significantly improved by adding crumb rubber into asphalt cement. Fig. 7 illustrates that Flow Number (FN) increases with crumb rubber increase. Elastomeric property of rubberized porous asphalt mix is observed by Dynamic Creep test. It affects rutting performance of asphalt mixtures by modifying two properties of asphalt cement. First, greater portion of deformations become recoverable. In addition, adding crumb rubber into asphalt cement makes it less sensitive to temperature rise and its elastic property is better preserved at high temperature. SBS has the same effect on rutting performance as $10 \%$ crumb rubber.

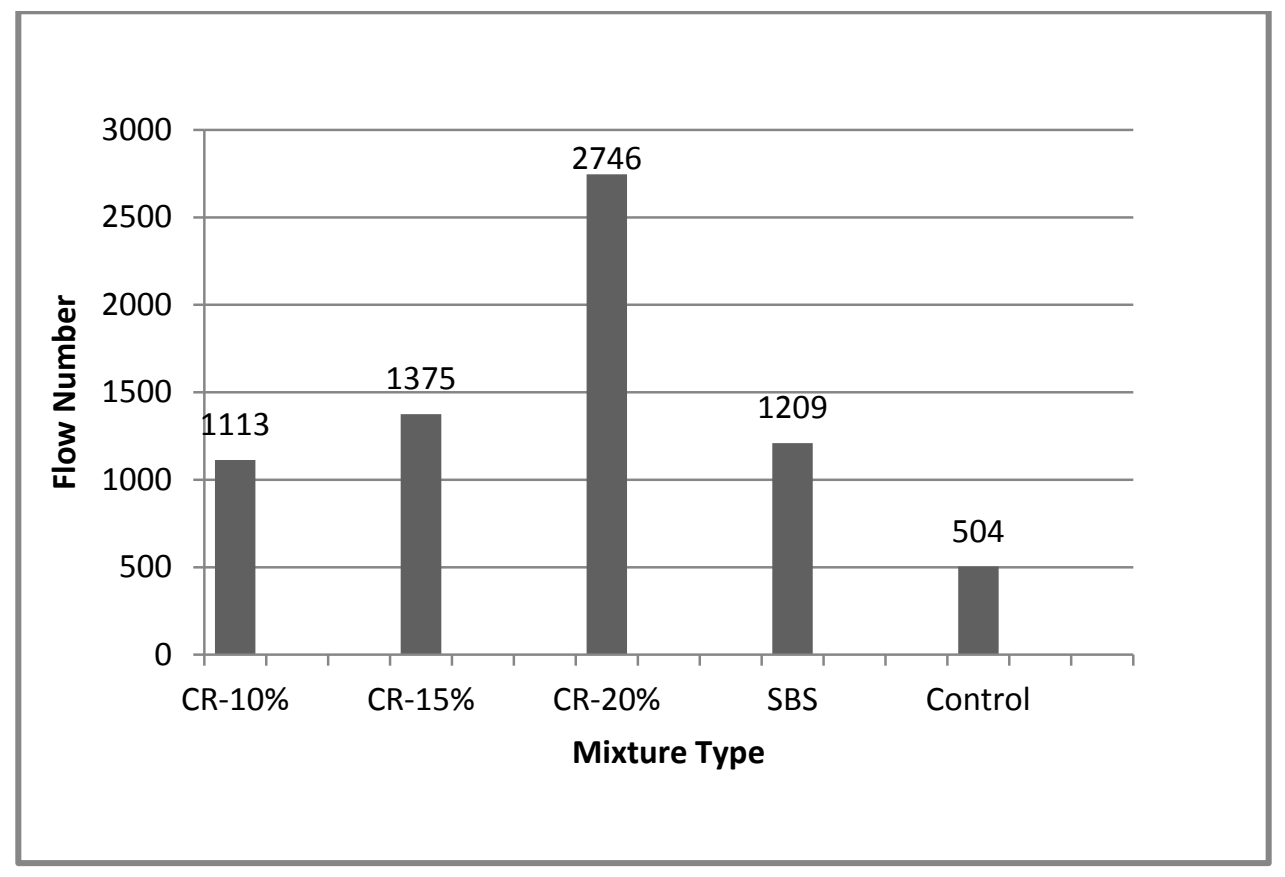

Fig. 7. Results of Dynamic Creep test 


\subsection{Wheel Tracking}

As shown in Fig. 8, rut depth of modified porous asphalt mixtures is significantly reduced compared to control one. SBS and CR-10\% have approximately the same rut depth showing they equally improve rutting performance of porous mixes. Similar to FN obtained from dynamic creep test, CR-20\% is the most rut resistance mixture followed by CR-15\%, CR-10\%, SBS, and control mixtures.

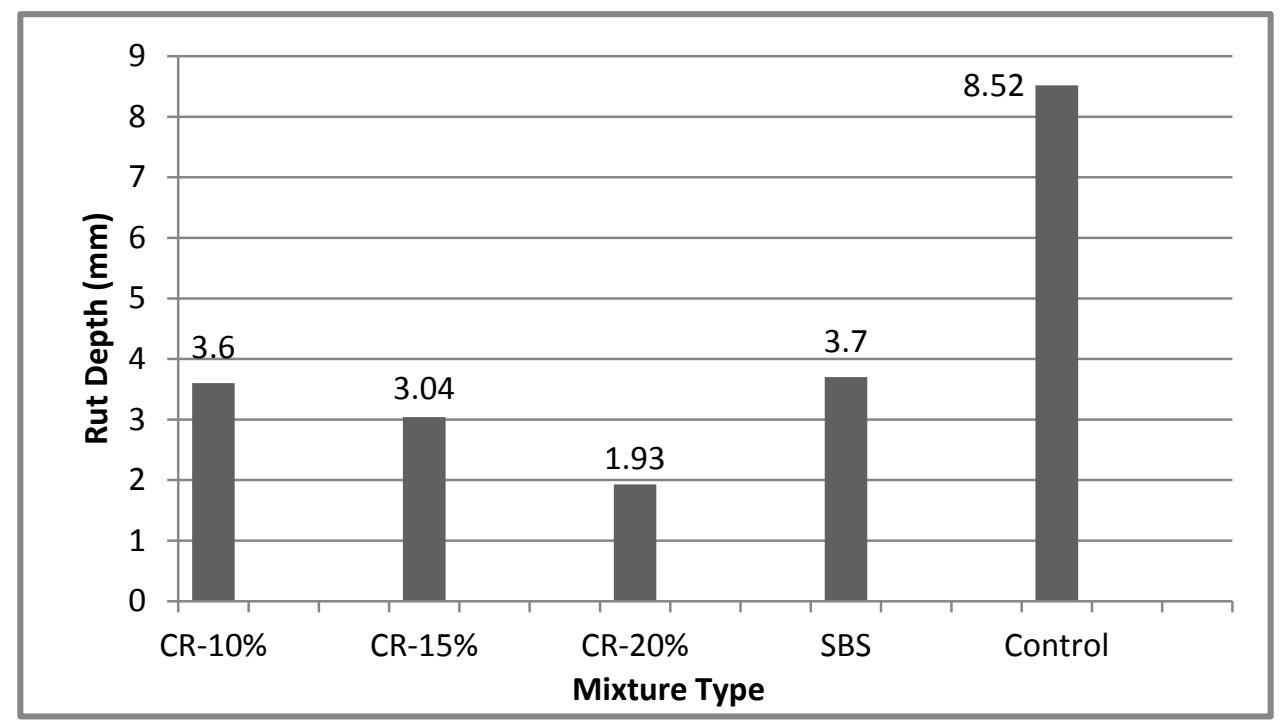

Fig. 8. Rut Depth results

\section{Conclusion}

This research investigated the impact of crumb rubber at different concentrations on rutting potential of porous asphalt and compared it with SBS modified porous asphalt. Both positive and negative effects were found regarding rutting performance of mixture containing Crumb rubber and SBS. The summary of tests results are as follows:

- Crumb rubber increases the amount of optimal binder content. On the other hand, SBS decreases it.

- Crumb rubber and SBS reduce porous asphalt potential of Draindown.

- Crumb rubber and SBS have negative effects on permeability of porous asphalt. They reduce the rate of permeability. However, it was found that the control, SBS, and $10 \%$ rubberized mixtures have coefficient of permeability greater than $100 \mathrm{~m} /$ day.

- Rutting resistance increases with crumb rubber content increase. Significant improvement is resulted by adding crumb rubber into asphalt cement. Mixture containing 20\% crumb rubber has maximum FN and the least rut depth. CR-10\% and SBS yield the same rutting performance.

\section{References}

Akbulut, H., \& Gürer, C. (2007). Use of aggregates produced from marble quarry waste in asphalt pavements. Building and Environment, 42(5), 1921-1930.

Aliha, M. R. M., Behbahani, H., Fazaeli, H., \& Rezaifar, M. H. (2014). Study of characteristic specification on mixed mode fracture toughness of asphalt mixtures. Construction and Building Materials, 54, 623-635.

Aliha, M. R. M., Behbahani, H., Fazaeli, H., \& Rezaifar, M. H. (2015). Experimental study on mode I fracture toughness of different asphalt mixtures. Scientia Iranica. Transaction A, Civil Engineering, 22(1), 120. 
Ameri, M., Mansourian, A., Pirmohammad, S., Aliha, M. R. M., \& Ayatollahi, M. R. (2012). Mixed mode fracture resistance of asphalt concrete mixtures. Engineering Fracture Mechanics, 93, 153167.

Brown, E. R., \& Cooley, L. A. (1999). Designing stone matrix asphalt mixtures for rut-resistant pavements (No. 425). Transportation Research Board.

Heidari-Rarani, M., Aliha, M. R. M., Shokrieh, M. M., \& Ayatollahi, M. R. (2014). Mechanical durability of an optimized polymer concrete under various thermal cyclic loadings-An experimental study. Construction and Building Materials, 64, 308-315.

IHAP Iran Highway Asphalt Paving Code (2003). Publication No. 234 Ministry of Road and Transportation Research and Education Center. Iran.

Kandhal, P. S., \& Mallick, R. B. (1999). Design of new-generation open-graded friction courses. NCAT Report, (99-3).

MansourKhaki, A., Samdzadeh, A., \& Jebalbarezi, M. (2015). Study of loading waveform, loading duration, rest period and stress level on fatigue life of asphalt mixtures. Engineering Solid Mechanics, 3(2), 93-102.

Nielsen, C. B., Bendtsen, H., Andersen, B., \& Larsen, H. J. (2005). Noise-reducing pavements in Japan: study tour report (No. 31).

Oliveira, J. R., Silva, H. M., Abreu, L. P., \& Fernandes, S. R. (2013). Use of a warm mix asphalt additive to reduce the production temperatures and to improve the performance of asphalt rubber mixtures. Journal of Cleaner Production, 41, 15-22.

Panda, M., \& Mazumdar, M. (2002). Utilization of reclaimed polyethylene in bituminous paving mixes. Journal of materials in civil engineering, 14(6), 527-530.

PIARC , Permanent International Association of Road Congresses (1993). Porous Asphalt World Road Association. PIARC Report of the Committee TC4-3.

Punith, V. S., Suresha, S. N., Raju, S., Bose, S., \& Veeraragavan, A. (2011). Laboratory Investigation of Open-Graded Friction-Course Mixtures Containing Polymers and Cellulose Fibers. Journal of Transportation Engineering, 138(1), 67-74.

Punith, V. S., \& Veeraragavan, A. (2007). Behavior of asphalt concrete mixtures with reclaimed polyethylene as additive. Journal of materials in civil engineering, 19(6), 500-507.

Santucci, L. (2001). Rut resistant asphalt pavements. Tech Topics.

Smith, H. A. (1992). Performance characteristics of open-graded friction courses (Vol. 180). Transportation Research Board.

Sol-Sánchez, M., Moreno-Navarro, F., García-Travé, G., \& Rubio-Gámez, M. C. (2015). Laboratory study of the long-term climatic deterioration of asphalt mixtures. Construction and Building Materials, 88, 32-40.

Takallou, H. B., \& Sainton, A. (1992). Advances in technology of asphalt paving materials containing used tire rubber. Transportation Research Record, (1339).

Xiao, F., \& Amirkhanian, S. N. (2010). Laboratory investigation of utilizing high percentage of RAP in rubberized asphalt mixture. Materials and structures, 43(1-2), 223-233.

Xiao, F., Putman, B. J., \& Amirkhanian, S. N. (2006, October). Laboratory investigation of dimensional changes of crumb rubber reacting with asphalt binder. In Proceeding Asphalt Rubber 2006 Conference (pp. 3144-3151).

Xiao, F., Zhao, P. W., \& Amirkhanian, S. N. (2009). Fatigue behavior of rubberized asphalt concrete mixtures containing warm asphalt additives. Construction and Building Materials, 23(10), 31443151.

Xiao, F., Zhao, W., Gandhi, T., \& Amirkhanian, S. N. (2010). Influence of antistripping additives on moisture susceptibility of warm mix asphalt mixtures. Journal of Materials in Civil Engineering, 22(10), 1047-1055. 